\title{
Post-reversible cerebral vasoconstriction syndrome headache
}

\author{
Yu-Hsiang Ling 1,2, Yen-Feng Wang 1,2, Jiing-Feng Lirng ${ }^{2,3}$, Jong-Ling Fuh 1,2,4, Shuu-Jiun Wang ${ }^{1,2,4}$ and \\ Shih-Pin Chen ${ }^{1,2,4,5,6^{*}}$ (D)
}

\begin{abstract}
Background: Chronic headache may persist after the remission of reversible cerebral vasoconstriction syndrome (RCVS) in some patients. We aimed to investigate the prevalence, characteristics, risk factors, and the impact of post-RCVS headache.

Methods: We prospectively recruited patients with RCVS and collected their baseline demographics, including psychological distress measured by Hospital Anxiety and Depression scale. We evaluated whether the patients developed post-RCVS headache 3 months after RCVS onset. The manifestations of post-RCVS headache and headache-related disability measured by Migraine Disability Assessment (MIDAS) scores were recorded.
\end{abstract}

Results: From 2017 to 2019, 134 patients with RCVS were recruited, of whom, 123 finished follow-up interviews (response rate 91.8\%). Sixty (48.8\%) patients had post-RCVS headache. Migrainous features were common in postRCVS headache. Post-RCVS headache caused moderate-to-severe headache-related disability (MIDAS score $>10$ ) in seven (11.7\%) patients. Higher anxiety level (odds ratio 1.21, $p=0.009$ ) and a history of migraine (odds ratio 2.59, $p=0.049)$ are associated with post-RCVS headache. Survival analysis estimated that $50 \%$ post-RCVS headache would recover in 389 days (95\% confidence interval: 198.5-579) after disease onset.

Conclusions: Post-RCVS headache is common, affecting half of patients and being disabling in one-tenth. Higher anxiety level and migraine history are risk factors. Half of the patients with post-RCVS headache would recover in about a year.

Keywords: Vasospasm, Chronic headache, Thunderclap headache, Prognosis, Prospective

\section{Introduction}

Reversible cerebral vasoconstriction syndrome (RCVS) is a disorder with distinguishing features of abrupt, excruciating headaches (mostly thunderclap headaches, $\mathrm{TCHs}$ ) and reversible segmental intracranial vasoconstriction revealed by neuroimaging [1]. Although most patients have a favourable outcome, RCVS remains a medical emergency due to its potential devastating

\footnotetext{
* Correspondence: chensp1977@gmail.com

${ }^{1}$ Department of Neurology, Neurological Institute, Taipei Veterans General Hospital, Taipei, Taiwan

${ }^{2}$ School of Medicine, National Yang Ming Chiao Tung University, Taipei, Taiwan

Full list of author information is available at the end of the article
}

complications such as ischemic stroke, intracranial haemorrhage, posterior reversible encephalopathy syndrome (PRES), and seizures.

Characterized by recurrent $\mathrm{TCHs}$ that are repeatedly elicited by triggers such as exertion, bathing, sexual intercourse, and Valsalva manoeuvres in a period of two to 3 weeks after disease onset, RCVS was traditionally considered as a monophasic disease that was limited to a period of 3 months. As new evidence [2, 3] has surfaced, RCVS is now recognized as a recurrent disorder with a recurrence rate of at least $5 \%$. Also, a few studies documented RCVS victims who continued to have chronic headache after remission of RCVS bout $[4,5]$. In a

(c) The Author(s). 2021 Open Access This article is licensed under a Creative Commons Attribution 4.0 International License, which permits use, sharing, adaptation, distribution and reproduction in any medium or format, as long as you give appropriate credit to the original author(s) and the source, provide a link to the Creative Commons licence, and indicate if changes were made. The images or other third party material in this article are included in the article's Creative Commons. licence, unless indicated otherwise in a credit line to the material. If material is not included in the article's Creative Commons licence and your intended use is not permitted by statutory regulation or exceeds the permitted use, you will need to obtain permission directly from the copyright holder. To view a copy of this licence, visit http://creativecommons.org/licenses/by/4.0/ The Creative Commons Public Domain Dedication waiver (http://creativecommons.org/publicdomain/zero/1.0/) applies to the data made available in this article, unless otherwise stated in a credit line to the data. 
retrospective study [6] of a cohort from two medical centres in the United States, $53 \%$ of patients $(n=45)$ reported chronic headaches after RCVS onset. Due to the emerging awareness regarding the importance of headaches that develop after RCVS remission, criteria for "persistent headache attributed to past RCVS" were proposed in the International Classification of Headache Disorders (2018), third edition (ICHD-3, code 6.7.3.3) [7]. However, no prospective long-term study has examined the prevalence of headaches that emerge and persist after the remission of TCHs during the RCVS bout. Therefore, this study aimed to investigate the prevalence and impact of post-RCVS headache and also to identify the risk factors.

\section{Methods}

\section{Participants and clinical settings}

We prospectively recruited patients with RCVS from the headache clinic of Taipei Veterans General Hospital, a 2802-bed national medical centre. The study period was from January 2017 to October 2019. The diagnosis of RCVS was made according to the International Classification of Headache Disorders, third edition beta version (ICHD-3 $\beta$ ) for those recruited before January 2018 and the International Classification of Headache Disorders, third edition (ICHD-3) for those recruited thereafter. The duration criterion that confines the clinical course of RCVS into 3 months (6.7.3.1, criterion D, ICHD-3) was omitted since the purpose of this study was to investigate the chronic headaches after RCVS.

\section{Diagnostic evaluations and treatments}

The diagnostic procedures and interventions administered to the patients have been detailed elsewhere $[3,8$, 9]. Baseline psychological distress was assessed by selfadministered Hospital Anxiety and Depression Scale (HADS). Within 2 days after the patient first visited the clinic, all clinical, neuroimaging, and laboratory investigations were performed to confirm cerebral vasoconstrictions and to exclude all other possible causes of TCHs, especially aneurysmal subarachnoid haemorrhage. Patients underwent oral $(30 \sim 60 \mathrm{mg} / 4 \mathrm{~h})$ or intravenous (0.5 $2 \mathrm{mg} /$ hour) nimodipine therapy with close blood pressure monitoring immediately after the diagnosis of RCVS was made. Sequential magnetic resonance angiography (MRA) and transcranial colour-coded sonography were performed to ensure the reversibility of vasoconstrictions, after which, nimodipine was discontinued.

\section{Evaluation of post-RCVS headaches}

In this study, a semi-structured follow-up interview focusing on post-RCVS headaches was arranged at least 3 months after RCVS onset. However, variations were allowed depending on participants' clinical condition and availability. Patients who failed to complete the first follow-up within 6 months after RCVS onset were considered as non-respondents. Any reported headaches were defined as post-RCVS headaches. Board-certified neurologists approached our participants with a questionnaire-based, semi-structured interview, and the characteristics of post-RCVS headaches (location, intensity, accompanying symptoms, and triggers) were recorded. The interview also evaluated the impact and disability due to post-RCVS headaches, applying the Migraine Disability Assessment (MIDAS), Taiwan version [10]. Of note, to avoid the MIDAS score from being confounded by headache attacks during the RCVS acute bouts, participants were instructed to trace back until the day they had their last thunderclap headache. The grading of headache-related disability was derived from the MIDAS scores: little or no disability (MIDAS scores $0-5$ ), mild disability (MIDAS scores 6-10), moderate disability (MIDAS scores 11-20), and severe disability (MIDAS scores $>20$ ). Patients with post-RCVS headaches were followed in the outpatient clinic of the headache centre, Taipei Veterans General Hospital.

\section{Standard protocol approvals, registrations, and patient consents}

This study was approved by the Institutional Review Board of Taipei Veterans General Hospital (2015-11005C and 2019-02-013A). All participants provided written informed consent before entering the study. All clinical investigations were conducted according to the principles expressed in the Declaration of Helsinki. The corresponding author has full access to all of the data in this study and has the final responsibility for the decision to submit research for publication.

\section{Statistics}

All analyses were performed with the SPSS software package, version 24.0 (IBM, Armonk, NY, USA). Descriptive data are presented as the mean \pm standard deviation, median (range), or number (percentage). The Student's $t$ test, Fisher's exact test, chi-squared test, or Mann-Whitney $U$ test was used for comparisons between groups, when appropriate. Logistic regression models were used to determine the clinical features associated with post-RCVS headaches, and the odds ratios (ORs) of the risk factors were reported. The probability of patients being free from post-RCVS headaches over time was analyzed by Kaplan-Meyer survival curves. The 95\% confidence intervals (CI) were reported. All calculated $p$ values were two-tailed. Statistical significance was defined as $p<0.05$. 


\section{Data availability}

The data that support the findings of this study are available from the corresponding author on reasonable request.

\section{Results}

\section{Demographics and characteristics of the participants}

During the study period, 134 patients fulfilled the inclusion criteria and joined the study. Of them, 123 patients completed the follow-up interviews (responder rate= 91.8\%). Figure 1 shows the flow chart of this study. The demographics and characteristics of the participants are shown in Table 1. Of the patients with RCVS, five had a history of RCVS, i.e., these five patients were having recurrent RCVS bouts when they were recruited. Another four patients developed recurrent RCVS during the follow-up period.

\section{Patients with post-RCVS headache}

Overall, 60 (48.8\%) participants reported post-RCVS headaches. There were no differences in age, sex, or triggers that elicited TCHs between patients with and without post-RCVS headaches. Patients with post-RCVS headaches had a higher level of anxiety, i.e., higher mean anxiety score of HADS at the first presentation to the clinic (Table 1). Compared to those without post-RCVS headache, the presence of a history of migraine prior to RCVS onset was more common in patients with postRCVS headaches. The frequency of hypertension, diabetes mellitus or dyslipidaemia in patients with post-
RCVS headaches did not differ from those without. Of note, two (3.3\%) patients had suffered from daily persistent headaches since the onset of TCHs during RCVS acute bouts.

\section{Characteristics of post-RCVS headache}

The characteristics of post-RCVS headache are summarized in Table 2. The headaches were frequently located in the occipital area (45.0\%), temporal area $(41.7 \%)$, and vertex (30.0\%). Migrainous features were not uncommon in post-RCVS headaches. Of the 60 patients with postRCVS headaches, $31.7 \%$ reported unilaterality, $44.1 \%$ reported pulsatile headache, and $25.0 \%$ reported that their headaches were aggravated by physical activities. Regarding the accompanying symptoms, $20.3 \%$ reported nausea, $10.0 \%$ reported vomiting, $16.7 \%$ reported photophobia, and $43.3 \%$ reported phonophobia. Overall, 12 (20\%) patients had post-RCVS headaches fulfilling the features of ICHD-3 migraine.

The post-RCVS headaches were mostly mild $(n=37$, $61.7 \%)$, while the rest were moderate $(n=18,30.0 \%)$ or severe $(n=5,8.3 \%)$. The average intensity score on a scale from zero to ten was $3.7 \pm 2.6$. Regarding the MIDAS score, most patients reported little or no disability; however, $11.7 \%$ reported that their post-RCVS headaches caused moderate-to-severe disability. Despite the fact that none of the analysed post-RCVS headaches were TCHs, $25(41.7 \%)$ patients reported at least one headache trigger, including sexual activity $(8.3 \%)$, cough

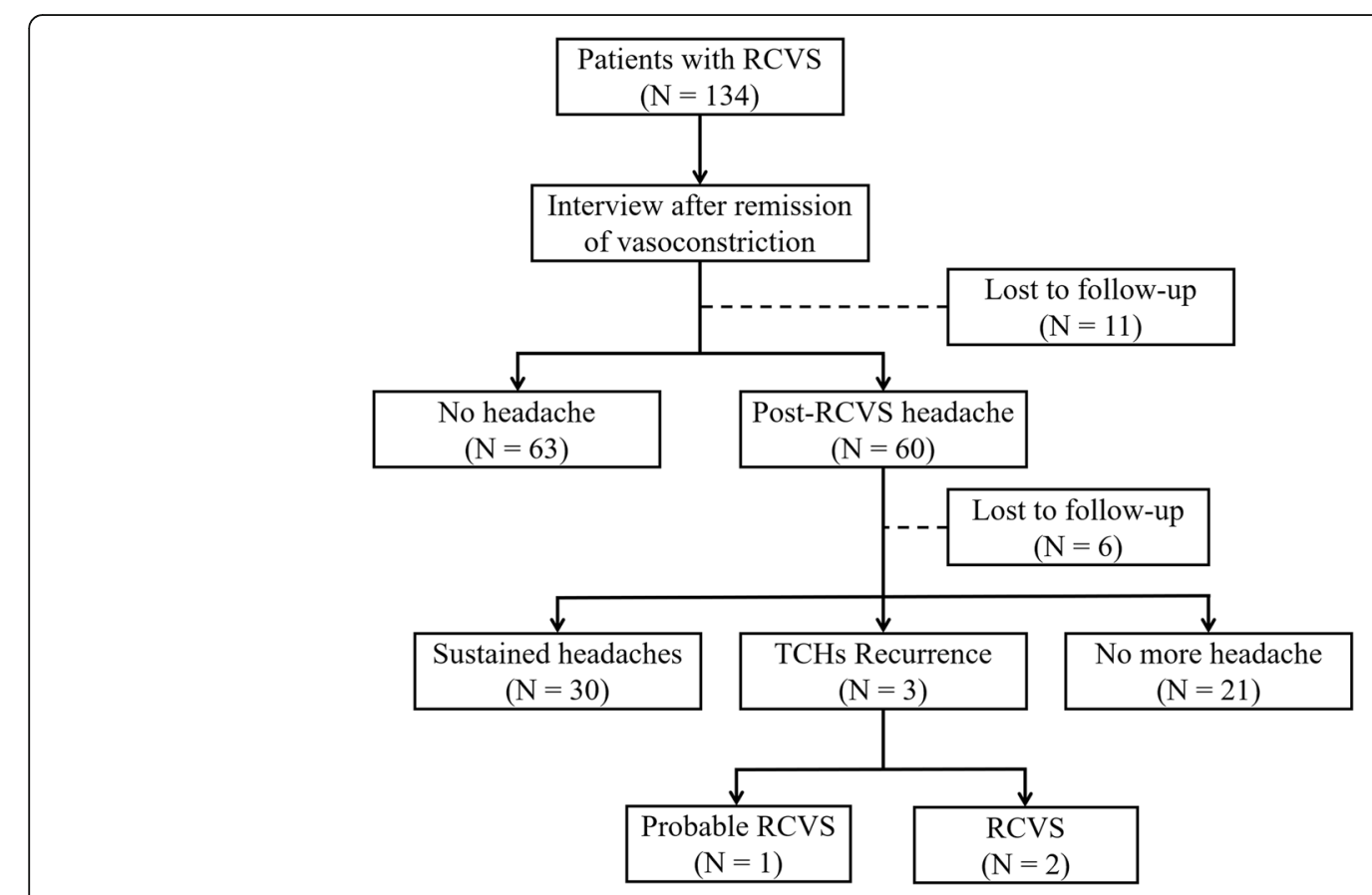

Fig. 1 Study design and flow chart 
Table 1 Demographics and characteristics of RCVS patients

\begin{tabular}{|c|c|c|c|c|}
\hline & \multirow{2}{*}{$\begin{array}{l}\text { All RCVS } \\
(N=123)\end{array}$} & \multicolumn{2}{|c|}{ Post-RCVS headache } & \multirow{2}{*}{$\begin{array}{l}P \\
\text { value }\end{array}$} \\
\hline & & Yes $(N=60)$ & No $(N=63)$ & \\
\hline Age (years) & $46.6 \pm 10.8$ & $46.3 \pm 9.7$ & $46.9 \pm 11.8$ & 0.745 \\
\hline Sex (female) & $86(69.9)$ & $45(75.0)$ & $41(65.1)$ & 0.230 \\
\hline Level of anxiety ${ }^{a}$ & $5.6 \pm 3.2$ & $6.5 \pm 3.1$ & $4.7 \pm 3.0$ & $0.004^{*}$ \\
\hline Level of depression ${ }^{a}$ & $4.3 \pm 3.4$ & $4.8 \pm 3.4$ & $3.8 \pm 3.5$ & 0.131 \\
\hline \multicolumn{5}{|l|}{ Past history } \\
\hline Any headache & $56(45.5)$ & $32(53.3)$ & $24(38.1)$ & 0.091 \\
\hline Migraine & $39(31.7)$ & $26(43.3)$ & $13(20.6)$ & $0.007^{*}$ \\
\hline Hypertension & $6(4.9)$ & $3(5.0)$ & $3(4.8)$ & 0.951 \\
\hline Diabetes Mellitus & $5(4.1)$ & $1(1.7)$ & $4(6.3)$ & 0.189 \\
\hline Dyslipidemia & $4(3.3)$ & $2(3.3)$ & $2(3.2)$ & 0.960 \\
\hline \multicolumn{5}{|l|}{ Triggers for $\mathrm{TCH}$} \\
\hline Sexual activities & $54(43.9)$ & $23(38.3)$ & $31(49.2)$ & 0.225 \\
\hline Cough \& Valsalva maneuvers & $54(43.9)$ & $24(40.0)$ & $30(47.6)$ & 0.395 \\
\hline Exertion & $29(23.6)$ & $15(25.0)$ & $14(22.2)$ & 0.717 \\
\hline Bathing & $32(26.0)$ & $14(23.3)$ & $18(28.6)$ & 0.508 \\
\hline Emotion & $17(13.8)$ & $8(13.3)$ & $9(14.3)$ & 0.878 \\
\hline Complications $^{\mathrm{b}}$ & $4(3.3)$ & $0(0)$ & $4(6.3)$ & N/A \\
\hline Convexity SAH & 2 & 0 & 2 & N/A \\
\hline $\mathrm{ICH}$ & 1 & 0 & 1 & N/A \\
\hline Ischemic stroke & 1 & 0 & 1 & N/A \\
\hline PRES & 2 & 0 & 2 & N/A \\
\hline Seizure & 1 & 0 & 1 & N/A \\
\hline \multicolumn{5}{|l|}{ Possible etiologies } \\
\hline Post-partum & 5 & 3 & 2 & N/A \\
\hline Vasoactive drugs & 2 & 1 & 1 & N/A \\
\hline History of prior RCVS & $5(4.1)$ & $3(5)$ & $2(3.2)$ & 0.608 \\
\hline
\end{tabular}

Data were presented as $\mathrm{n}(\%)$ or mean $\pm \mathrm{SD} .{ }^{*} p<0.05$

${ }^{a}$ Levels of anxiety and depression were measured by Hospital Anxiety and Depression Scale

${ }^{b}$ A patient was complicated with more than one complication

ICH intracerebral hemorrhage; N/A not applicable for calculation; PRES posterior reversible encephalopathy syndrome; RCVS reversible cerebral vasoconstriction

syndrome; SAH subarachnoid hemorrhage; $T C H$ thunderclap headache

and other Valsalva manoeuvres (15.0\%), exertion (8.3\%), bathing (6.7\%), and emotion (33.3\%) (Table 2).

\section{Factors associated with post-RCVS headaches}

Clinical features, including demographics, prior medical history, and triggers for TCHs as well as accompanying symptoms in RCVS were analyzed to identify predictors for post-RCVS headaches using logistic regression models (Table 3 ). The univariate analyses showed that having a prior history of migraine and a higher level of anxiety were associated with the presence of post-RCVS headaches. These factors remained significant according to a multivariable analysis (history of migraine: $\mathrm{OR}=$ 2.59, $95 \%$ CI $1.01 \sim 6.69, p=0.049$; anxiety level: $\mathrm{OR}=$ $1.21,95 \%$ CI $1.05 \sim 1.39, p=0.009$ ).

\section{Follow-ups of post-RCVS headaches}

Fifty-four (90\%) patients with post-RCVS headaches were followed at the outpatient clinic after the interview. The mean follow-up duration was $271.1 \pm 186.8$ days after their first visits. Thirty (55.6\%) patients continued to have headaches, with the most extended follow-up duration up to 758 days (Fig. 2). The median headachefree probability of post-RCVS headache was 389.0 days (95\% CI: 198.5-579 days). Post-RCVS headaches resolved in 21 patients (38.9\%). Three patients developed thunderclap headaches during the clinical follow-ups. Two of them were confirmed to have RCVS relapse based on MRAs. The one without apparent vasoconstriction was diagnosed with probable RCVS after excluding other etiologies. 
Table 2 Headache features of post-RCVS headaches

\begin{tabular}{|c|c|}
\hline & Post RCVS headache $(N=60)$ \\
\hline \multicolumn{2}{|l|}{ Location } \\
\hline Frontal & $7(11.7)$ \\
\hline Temporal & $25(41.7)$ \\
\hline Vertex & $18(30.0)$ \\
\hline Occipital & $27(45.0)$ \\
\hline Whole head & $5(8.3)$ \\
\hline Headache intensity ${ }^{a}$ & $3.7 \pm 2.6$ \\
\hline \multicolumn{2}{|l|}{ Migrainous features } \\
\hline Unilateral & $19(31.7)$ \\
\hline Pulsating & $26(44.1)$ \\
\hline Aggravated by physical activity & $15(25.0)$ \\
\hline Nausea & $12(20.3)$ \\
\hline Vomiting & $6(10.0)$ \\
\hline Photophobia & $10(16.7)$ \\
\hline Phonophobia & $26(43.3)$ \\
\hline \multicolumn{2}{|l|}{ Fulfill ICHD-3 criteria } \\
\hline Migraine & $12(20.0)$ \\
\hline \multicolumn{2}{|l|}{ Disability ${ }^{\mathrm{b}}$} \\
\hline Little or no disability & $47(78.3)$ \\
\hline Mild disability & $6(10.0)$ \\
\hline Moderate disability & $1(1.7)$ \\
\hline Severe disability & $6(10.0)$ \\
\hline \multicolumn{2}{|l|}{ Triggers } \\
\hline None & $35(58.3)$ \\
\hline Sexual activities & $5(8.3)$ \\
\hline Cough \& Valsalva maneuvers & $9(15.0)$ \\
\hline Exertion & $5(8.3)$ \\
\hline Bathing & $4(6.7)$ \\
\hline Emotion & 20 (33.3) \\
\hline
\end{tabular}

Data were presented as $\mathrm{n}(\%)$, mean $\pm \mathrm{SD}$

a Headache intensity was measured with an 11-point numeric rating scale where 0 represents no pain at all and 10 represents the worst imaginable pain

${ }^{b}$ Disability was measured by the Migraine Disability Assessment

ICHD-3 The International Classification of Headache Disorders, 3rd Edition;

RCVS reversible cerebral vasoconstriction syndrome

\section{Discussion}

In this prospective longitudinal follow-up study, about half of our RCVS participants still suffered from chronic headaches at 3 months after RCVS onset. Half of them $(30 / 60,50 \%)$ required long-term medical attention, lasting up to 2 years. Furthermore, we discovered that the RCVS patients with a history of migraine and a higher anxiety level were at risk for post-RCVS headaches. To the best of our knowledge, this is the first prospective and systematic study investigating the frequency and risk factors of headaches after RCVS.
We found that headaches after RCVS onset were common and mostly mild in intensity as well as headacherelated disability, consistent with the finding of a previous retrospective [6] study that recruited 45 patients from various ethnicities. However, post-RCVS headaches caused moderate to severe disability in $10 \%$ of patients, who required chronic medical attention. In addition, we identified two patients (3.3\%) who suffered from daily persistent headaches since RCVS onset, which was in line with previous reports demonstrating five cases presenting with new daily persistent headaches after RCVS onset $[4,5]$.

Our study found that having a history of migraine is a risk factor that predicts post-RCVS headaches. Having a prior history of migraine is not unusual for patients with RCVS; in our prior cohort with 210 RCVS patients, $21 \%$ of patients had a history of migraine [3]. Also, migrainous features are not uncommon in post-RCVS headache. Up to $78.3 \%$ (47/60) of patients had at least one migrainous feature of their headaches after RCVS. These findings suggested a connection linking migraine, RCVS, and post-RCVS headache, which has an impact on both clinical and pathophysiological aspects. First, when treating these patients, especially when they develop postRCVS headaches, physicians should be cautious about the administration of triptans and ergots since their potential vasoactive side effects on intracranial arteries. Second, whether migraine is a potential risk factor for RCVS is still under debate; however, shared mechanisms, including endothelial cell dysfunction, linking migraine and RCVS have been proposed by previous studies [11-14]. In addition, it has been shown that patients with migraine have an altered functional connectivity in pain-processing areas, including the periaqueductal grey area [15], rostral anterior cingulate and prefrontal cortex [16, 17], and insula [18]. We hypothesize that during the acute bouts of RCVS, the trigeminovascular nociceptive pathway is activated and sensitized due to the repeated attack of thunderclap headaches, causing chronic headaches after the acute phase of RCVS, especially in patients with migraine whose pain perception networks might have already been altered. We also identified that the anxiety level on the first presentation to clinics was associated with the occurrence of post-RCVS headaches. From the past studies, we learned that pain perception may be exacerbated by higher anxiety status, probably through altering the activity of the hippocampal network $[19,20]$, which may explain our findings.

The pathophysiology of RCVS remains unknown; thus, demystifying the mechanism of post-RCVS headache will be even more challenging. However, studies focusing on RCVS pathophysiology have given us some hints. First, a study conducted by a Korean research team 
Table 3 Factors associated with post-RCVS headache

\begin{tabular}{|c|c|c|c|c|}
\hline & \multicolumn{2}{|l|}{ Univariate } & \multicolumn{2}{|l|}{ Multivariable } \\
\hline & OR $(95 \% \mathrm{Cl})$ & $P$ value & OR $(95 \% \mathrm{Cl})$ & $P$ value \\
\hline \multicolumn{5}{|l|}{ Past medical history } \\
\hline Any headache & $1.76(0.85,3.65)$ & 0.130 & & \\
\hline Migraine & $2.79(1.25,6.23)$ & $0.013^{*}$ & $2.59(1.001,6.69)$ & $0.049^{*}$ \\
\hline Hypertension & $1.08(0.21,5.59)$ & 0.931 & & \\
\hline Diabetes mellitus & $0.27(0.29,2.54)$ & 0.253 & & \\
\hline Dyslipidemia & $1.12(0.15,8.45)$ & 0.913 & & \\
\hline Level of anxiety ${ }^{a}$ & $1.21(1.05,1.40)$ & $0.007^{*}$ & $1.21(1.05,1.39)$ & $0.009^{*}$ \\
\hline Level of depression ${ }^{\mathrm{a}}$ & $1.08(0.96,1.22)$ & 0.188 & & \\
\hline \multicolumn{5}{|l|}{ Triggers for TCHs } \\
\hline Sexual activities & $0.65(0.24,1.79)$ & 0.406 & & \\
\hline Cough \& Valsalva maneuvers & $0.64(0.30,1.36)$ & 0.242 & & \\
\hline Exertion & $1.27(0.54,2.97)$ & 0.584 & & \\
\hline Bath & $0.71(0.30,1.70)$ & 0.445 & & \\
\hline Emotion & $0.80(0.28,2.29)$ & 0.674 & & \\
\hline
\end{tabular}

The results were controlled by age and sex. ${ }^{*} p<0.05 ;{ }^{a}$ Levels of anxiety and depression were measured by Hospital Anxiety and Depression Scale $R C V S$ reversible cerebral vasoconstriction syndrome; $O R$ odds ratio; $\mathrm{Cl}$ confidence interval; $T C H$ s thunderclap headaches

demonstrated that patients with RCVS have impaired cerebral endothelial functions, and, in some patients, the endothelial cell dysfunction had not recovered at the three-month follow-up [14]. Moreover, our previous study [21] assessing the autonomic function by analyzing heart rate variability in RCVS patients demonstrated that RCVS patients had autonomic dysfunction during acute bouts, and it remained abnormal compared with healthy controls even after the remission of RCVS. These findings suggest that some patients remain abnormal after RCVS remission, providing a plausible physiological basis for post-RCVS headache. It is also possible that in vulnerable patients, their pain matrix is sensitized by TCHs or the biological consequences of RCVS, such as disruption to the blood-brain barrier. A prospective, cohort study is warranted to elucidate the causality and differentiate whether these findings resulted from the

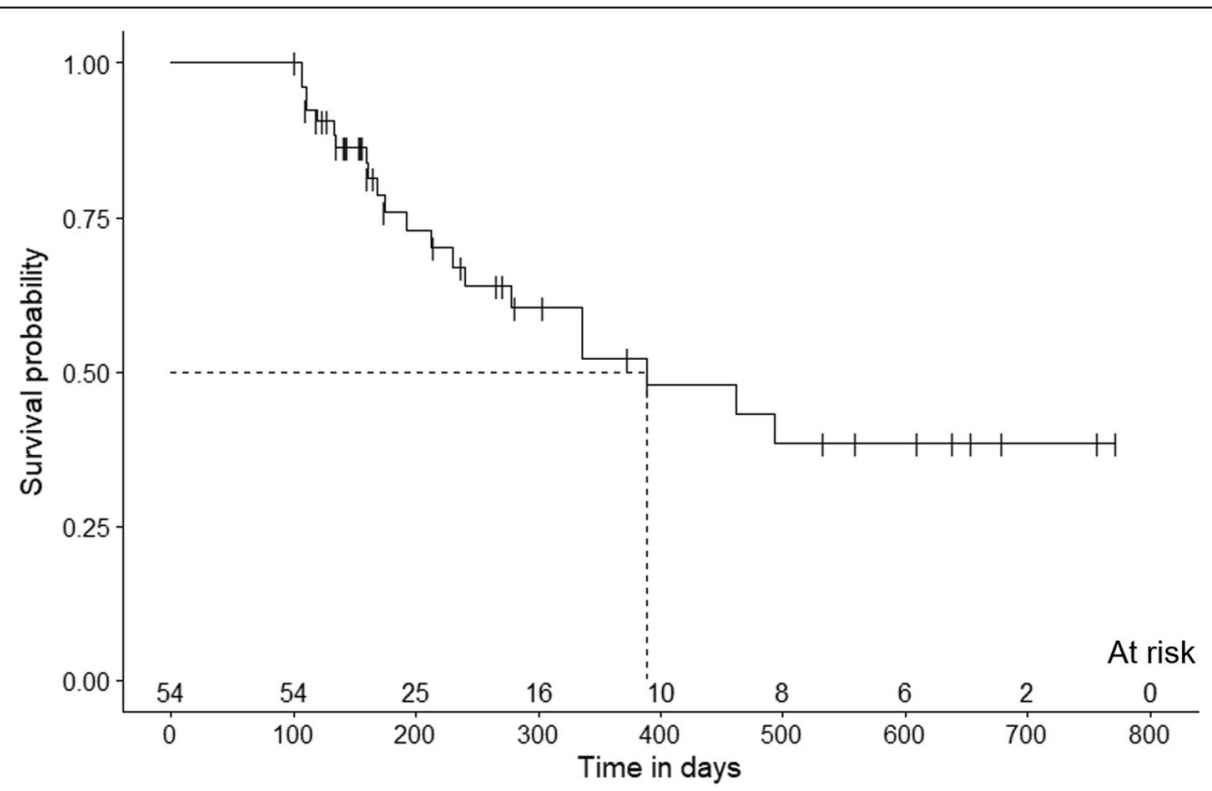

Fig. 2 The survival curve of remission of post-RCVS headache 
innate biological traits of RCVS patients or subclinical sequelae after RCVS remission as we suspected.

Our study has limitations. First, we assessed the baseline anxiety levels of patients on their first presentation to clinics. It is difficult to distinguish whether the anxiety we referred to represents trait anxiety or state anxiety at evaluation. We believe that state anxiety may play an essential role because the HADS required the participants to answer the questions based on their condition in the past week, and all patients had just recently suffered from TCHs, which could be considered as major and devastating events. However, it is difficult to entirely exclude the possibility that the trait anxiety of a patient confounded the anxiety score we measured. In fact, it is likely that the anxiety level we measured in this study represented both the state and trait anxiety. Second, since all patients were treated initially with nimodipine, the effect of nimodipine on the occurrence of postRCVS headaches could not be evaluated in this study. Third, it is methodologically challenging to distinguish post-RCVS headache from migraine attacks in patients with pre-existing migraine. In certain cases, it is almost impossible for physicians, or even the patients themselves, to determine the differences between a preexisting migraine and a chronic headache after RCVS. Following the context, diagnosing a migraine-like headache as post-RCVS headache is not against the principles of ICHD criteria. On the other hand, post-RCVS headache may not be completely equivalent to migraine even when it fulfils the diagnostic criteria of migraine since some common features in post-RCVS headache, like having headache triggers including sex activities, Valsalva-like manoeuvres, bathing, and emotional changes, were not seen in migraine. Finally, we believe that post-RCVS headaches should be distinguished from migraine since we are wary of using abortive or preventive medications that are potentially vasoconstrictive in patients with post-RCVS headache.

\section{Abbreviations \\ Cl: Confident interval; HADS: Hospital Anxiety and Depression Scale; ICHD: International classification of headache disorder; MIDAS: Migraine Disability Assessment; MRA: Magnetic resonance angiography; OR: Odds ratio; RCVS: Reversible cerebral vasoconstriction syndrome; TCH: Thunderclap headache}

\section{Acknowledgements}

We thank all patients in this study for their generous participation.

\section{Authors' contributions}

SPC had full access to all of the data in the study and take the responsibility for the integrity of the data and the accuracy of the data analysis. SJW and SPC were involved the study conception and design. YHL and SPC were responsible for acquisition, analysis, and interpretation of data. YHL and SPC were responsible for manuscript drafting. YHL, YFW, JFL, JLF, SJW, and SPC contributed to critical revision of the manuscript for important intellectual content. All authors provided the final approval of the version to be published.

\section{Funding}

This work was supported by the Brain Research Center, National Yang Ming Chiao Tung University from The Featured Areas Research Center Program within the framework of the Higher Education Sprout Project by the Ministry of Education (MOE) in Taiwan (to SJW \& SPC); Ministry of Science and Technology of Taiwan [MOST-108-2314-B-010-022-MY3] (to SPC), [MOST-1082321-B-010-014-MY2] (to SJW), and [MOST-110-2321-B-010-005] (to SJW); and Taipei Veterans General Hospital [VGH-109-C-139] (to SPC). The funders had no role in study design, data collection and analysis, decision to publish, or preparation of the manuscript.

\section{Availability of data and materials}

The data that support the findings of this study are available from the corresponding author on reasonable request.

\section{Declarations}

\section{Ethics approval and consent to participate}

The study was approved by the Institutional Review Board of the Taipei Veterans General Hospital, Taipei, Taiwan (2015-11-005C and 2019-02-013A). Written informed consent was obtained from each participant prior to entering the trial. All clinical investigations were conducted according to the principles expressed in the Declaration of Helsinki. All collected information was de-identified before statistical analysis.

\section{Consent for publication}

Not applicable.

\section{Competing interests}

The authors declared no potential conflicts of interest with respect to the research, authorship, and/or publication of this article.

\section{Author details \\ ${ }^{1}$ Department of Neurology, Neurological Institute, Taipei Veterans General Hospital, Taipei, Taiwan. ${ }^{2}$ School of Medicine, National Yang Ming Chiao Tung University, Taipei, Taiwan. ${ }^{3}$ Department of Radiology, Taipei Veterans General Hospital, Taipei, Taiwan. ${ }^{4}$ Brain Research Center, National Yang Ming Chiao Tung University, Taipei, Taiwan. ${ }^{5}$ Division of Translational Research, Department of Medical Research, Taipei Veterans General Hospital, Taipei, Taiwan. ${ }^{6}$ Institute of Clinical Medicine, National Yang Ming Chiao Tung University, Taipei, Taiwan.}

Received: 6 January 2021 Accepted: 12 March 2021

Published online: 25 March 2021

\section{References}

1. Calabrese LH, Dodick DW, Schwedt TJ, Singhal AB (2007) Narrative review: reversible cerebral vasoconstriction syndromes. Ann Intern Med 146(1):3444. https://doi.org/10.7326/0003-4819-146-1-200701020-00007

2. Boitet R, de Gaalon S, Duflos C, Marin G, Mawet J, Burcin C, Roos C, Fiedler U, Bousser MG, Ducros A (2020) Long-term outcomes after reversible cerebral vasoconstriction syndrome. Stroke 51(2):670-673. https://doi.org/1 0.1161 /STROKEAHA.119.027703

3. Chen S-P, Fuh J-L, Lirng J-F, Wang YF, Wang SJ (2015) Recurrence of reversible cerebral vasoconstriction syndrome: a long-term follow-up study. Neurology 84(15):1552-1558. https://doi.org/10.1212/WNL.00000000000014 73

4. Rozen TD, Beams $J L$ (2013) New daily persistent headache with a thunderclap headache onset and complete response to nimodipine (a new distinct subtype of NDPH). J Headache Pain 14(1):100. https://doi.org/10.11 86/1129-2377-14-100

5. Jamali SA, Rozen TD (2019) An RCVS Spectrum disorder? New daily persistent headache starting as a single thunderclap headache (3 new cases). Headache 59(5):789-794. https://doi.org/10.1111/head.13495

6. John S, Singhal AB, Calabrese L, Uchino K, Hammad T, Tepper S, Stillman M, Mills B, Thankachan T, Hajj-Ali RA (2016) Long-term outcomes after reversible cerebral vasoconstriction syndrome. Cephalalgia 36(4):387-394. https://doi.org/10.1177/0333102415591507

7. (2018) Headache Classification Committee of the International Headache Society (IHS) The International Classification of Headache Disorders, 3rd edition. Cephalalgia 38:1-211. https://doi.org/10.1177/0333102417738202 
8. Chen S-P, Fuh J-L, Wang S-J, Chang FC, Lirng JF, Fang YC, Shia BC, Wu JC (2010) Magnetic resonance angiography in reversible cerebral vasoconstriction syndromes. Ann Neurol 67:648-656. https://doi.org/10.1 002/ana.21951

9. Chen S-P, Chou K-H, Fuh J-L, Huang YH, Huang CC, Lirng JF, Wang YF, Lin CP, Wang SJ (2018) Dynamic changes in white matter Hyperintensities in reversible cerebral vasoconstriction syndrome. JAMA Neurol 75(9):11061113. https://doi.org/10.1001/jamaneurol.2018.1321

10. Hung P-H, Fuh J-L, Wang S-J (2006) Validity, reliability and application of the Taiwan version of the migraine disability assessment questionnaire. J Formos Med Assoc 105:563-568. https://doi.org/10.1016/S0929-664 6(09)60151-0, 7

11. Lee S-T, Chu K, Jung K-H et al (2008) Decreased number and function of endothelial progenitor cells in patients with migraine. Neurology 70(17): 1510-1517. https://doi.org/10.1212/01.wnl.0000294329.93565.94

12. Rodríguez-Osorio X, Sobrino T, Brea D et al (2012) Endothelial progenitor cells: a new key for endothelial dysfunction in migraine. Neurology 79(5): 474-479. https://doi.org/10.1212/WNL.0b013e31826170ce

13. Chen S-P, Wang Y-F, Huang P-H, Chi CW, Fuh JL, Wang SJ (2014) Reduced circulating endothelial progenitor cells in reversible cerebral vasoconstriction syndrome. J Headache Pain 15(1):82. https://doi.org/10.11 86/1129-2377-15-82

14. Choi HA, Lee MJ, Chung C-S (2017) Cerebral endothelial dysfunction in reversible cerebral vasoconstriction syndrome: a case-control study. J Headache Pain 18(1):29. https://doi.org/10.1186/s10194-017-0738-x

15. Mainero C, Boshyan J, Hadjikhani N (2011) Altered functional magnetic resonance imaging resting-state connectivity in periaqueductal gray networks in migraine. Ann Neurol 70(5):838-845. https://doi.org/10.1002/a na.22537

16. Xue $T$, Yuan $K$, Cheng $P$, Zhao L, Zhao L, Yu D, Dong $T$, von Deneen KM, Gong Q, Qin W, Tian J (2013) Alterations of regional spontaneous neuronal activity and corresponding brain circuit changes during resting state in migraine without aura. NMR Biomed 26(9):1051-1058. https://doi.org/10.1 002/nbm.2917

17. Yu D, Yuan K, Zhao L, Zhao L, Dong M, Liu P, Wang G, Liu J, Sun J, Zhou G, Deneen KM, Liang F, Qin W, Tian J (2012) Regional homogeneity abnormalities in patients with interictal migraine without aura: a restingstate study. NMR Biomed 25(5):806-812. https://doi.org/10.1002/nbm.1796

18. Xue T, Yuan K, Zhao L, Yu D, Zhao L, Dong T, Cheng P, von Deneen KM, Qin W, Tian J (2012) Intrinsic brain network abnormalities in migraines without aura revealed in resting-state fMRI. PLoS One 7(12):e52927. https:// doi.org/10.1371/journal.pone.0052927

19. Tang J, Gibson SJ (2005) A psychophysical evaluation of the relationship between trait anxiety, pain perception, and induced state anxiety. J Pain 6(9):612-619. https://doi.org/10.1016/j.jpain.2005.03.009

20. Ploghaus A, Narain C, Beckmann CF, Clare S, Bantick S, Wise R, Matthews PM, Rawlins JNP, Tracey I (2001) Exacerbation of pain by anxiety is associated with activity in a hippocampal network. J Neurosci 21(24):98969903. https://doi.org/10.1523/JNEUROSCI.21-24-09896.2001

21. Chen S-P, Yang AC, Fuh J-L, Wang S-J (2013) Autonomic dysfunction in reversible cerebral vasoconstriction syndromes. J Headache Pain 14(1):94. https://doi.org/10.1186/1129-2377-14-94

\section{Publisher's Note}

Springer Nature remains neutral with regard to jurisdictional claims in published maps and institutional affiliations.

Ready to submit your research? Choose BMC and benefit from:
- fast, convenient online submission
- thorough peer review by experienced researchers in your field
- rapid publication on acceptance
- support for research data, including large and complex data types
- gold Open Access which fosters wider collaboration and increased citations
- maximum visibility for your research: over 100M website views per year
At BMC, research is always in progress.
Learn more biomedcentral.com/submissions

